\title{
BMJ Open Failure to address potential bias in non- randomised controlled clinical trials may cause lack of evidence on patient- reported outcomes: a method study
}

\author{
Frank Peinemann, ${ }^{1}$ Alexander Michael Labeit, ${ }^{2}$ Christian Thielscher, ${ }^{3}$ \\ Michael Pinkawa ${ }^{4}$
}

To cite: Peinemann F, Labeit AM, Thielscher C, et al. Failure to address potential bias in nonrandomised controlled clinical trials may cause lack of evidence on patient-reported outcomes: a method study. BMJ Open 2014;4:e004720. doi:10.1136/bmjopen-2013004720

- Prepublication history for this paper is available online. To view these files please visit the journal online (http://dx.doi.org/10.1136/ bmjopen-2013-004720).

Parts of the study have been presented at 19th Cochrane Colloquium 19-22 October 2011 in Madrid, Spain.

Received 19 December 2013 Revised 28 April 2014 Accepted 13 May 2014

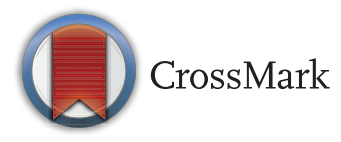

For numbered affiliations see end of article.

Correspondence to Frank Peinemann; pubmedprjournal@gmail.com

\section{ABSTRACT}

Objectives: We conducted a workup of a previously published systematic review and aimed to analyse why most of the identified non-randomised controlled clinical trials with patient-reported outcomes did not match a set of basic quality criteria.

Setting: There were no limits on the level of care and the geographical location.

Participants: The review evaluated permanent interstitial low-dose rate brachytherapy in patients with localised prostate cancer and compared that intervention with alternative procedures such as external beam radiotherapy, radical prostatectomy and no primary therapy.

Primary outcome measure: Fulfilment of basic inclusion criteria according to a Participants, Interventions, Comparisons, Outcomes (PICO) framework and accomplishment of requirements to contain superimposed risk of bias.

Results: We found that 21 of 50 excluded nonrandomised controlled trials did not meet the PICO inclusion criteria. The remaining 29 studies showed a lack in the quality of reporting. The resulting flaws included attrition bias due to loss of follow-up, lack of reporting baseline data, potential confounding due to unadjusted data and lack of statistical comparison between groups.

Conclusions: With respect to the reporting of patientreported outcomes, active efforts are required to improve the quality of reporting in non-randomised controlled trials concerning permanent interstitial lowdose rate brachytherapy in patients with localised prostate cancer.

\section{INTRODUCTION}

The present paper reports a workup of a previously published systematic review. ${ }^{1}$ It may be regarded as a methodological supplement adding information on a subset of excluded studies. We have compared permanent interstitial low-dose rate brachytherapy, with radical prostatectomy, external beam

\section{Strengths and limitations of this study}

We conducted a comprehensive literature search and strictly adhered to the projected methodology.

- We identified a lack of quality in non-randomised controlled clinical trials reporting patient-reported outcomes, analysed the cause and suggested possible improvements in designing studies in the future.

- The analysis is confined to a single disease and a specific treatment and conclusions drawn from its results may not be generalisable to other diseases and treatments.

- The limits for the inclusion of studies are arbitrarily set.

radiotherapy and 'no primary therapy' in patients with localised prostate cancer categorised as T1 to T2. We used the term 'no primary therapy' to accommodate different types of observation including active surveillance, watchful waiting and observing without a distinctive management. As a result, we included one randomised controlled trial (RCT) and 30 non-randomised controlled clinical trials (CCT). The primary outcome was overall survival. The secondary outcomes were clinically defined disease-free survival, biochemical recurrence-free survival, physician-reported severe adverse events and patient-reported outcomes (PROs) such as function and bother scores as well as generic and disease-related health-related quality of life. We concluded that the current evidence is insufficient to allow a definitive conclusion about overall survival. Radical prostatectomy and external beam radiotherapy can severely affect the structural integrity of neighbouring organs and their functions and can also cause considerable long-term impairment of health-related quality of life. With a view of 
expecting similar survival but a tremendous difference of adverse events between treatment alternatives, valid data on health-related quality of life could tip the balance. At the least, we assume that shared decision-making and consideration of patients' preferences in searching for the best individual treatment would rely on information on the health-related quality-of-life data. Of the 30 included non-randomised studies, 13 studies reported PROs, that is, only the patients provided the information. ${ }^{2}$ During the study selection process, we experienced that we excluded another 50 non-randomised PRO studies. We found it a pity that we could not use the data. We had the impression that a considerable number of studies were excluded because of a lack in the quality of reporting. Therefore, we wanted to summarise the reasons for excluding those PRO studies and make the authors of PRO studies aware of some basic requirements for reporting of comparative PRO data to achieve higher acceptance in the scientific community. The importance of reporting PRO has been addressed by the Consolidated Standards of Reporting Trials (CONSORT) group $^{3}$ which recently published a PRO extension to their acclaimed previous statement. ${ }^{4}$ It may be wise to build a PRO extension to the STrengthening the Reporting of OBservational studies in Epidemiology (STROBE) statement ${ }^{5}$ that addresses specific issues of observational studies.

The first aim of this study was to assess whether the excluded studies met the basic inclusion criteria using the PICO framework. The second aim was to ensure whether the excluded studies met the requirements to contain high risk of bias.

\section{MATERIALS AND METHODS \\ Study inclusion criteria}

We defined the inclusion criteria according to the PICO framework that should include four essential constituents, that is, the type of participants $(\mathrm{P})$, intervention (I), comparator $(\mathrm{C})$ and outcome $(\mathrm{O}){ }^{6}$ The four PICO items can be supplemented by timing $(\mathrm{T})$ and setting (S), two other important features of a systematic review, to create the so-called PICOTS typology. ${ }^{7}$ A further extension embraces the study design (SD) to complete all major items of a search strategy (PICOTS-SD). ${ }^{8}$

\section{Population}

Initial and present publication

Localised prostate cancer is defined by the categories $\mathrm{T} 1$ to T2 of the tumour-node-metastasis staging system ${ }^{9}$ if combined with the absence of regional lymph node metastasis and distant metastasis.

\section{Intervention}

\section{Initial and present publication}

Brachytherapy ${ }^{10}$ is short-distance radiotherapy placing radiation sources with different duration and rates of dose delivery in or near tumours. ${ }^{11}$ Permanent interstitial low-dose rate brachytherapy means implanting of low-energy radioactive sources emitting radiation, which are contained in titanium pellets of the size of rice grains called seeds. ${ }^{12}$

\section{Comparator}

\section{Initial and present publication}

The European Association of Urology suggested three different treatment concepts for localised prostate cancer in addition to permanent interstitial low-dose rate brachytherapy ${ }^{10}$ : radical prostatectomy, external beam radiotherapy and different types of observation including active surveillance, watchful waiting and observing without distinctive management.

\section{Outcome}

\section{Initial publication}

Overall survival, cancer-specific survival, disease-free survival, biochemical recurrence-free survival, severe adverse events and PROs. PROs comprised function and bother scores as well as generic and disease-related health-related quality of life.

\section{Present publication}

Fulfilment of basic inclusion criteria according to a PICO framework by the excluded CCT. Accomplishment of requirements to contain superimposed risk of bias in addition to the high risk of bias caused by the lack of randomisation framework by the excluded CCT.

\section{Timing}

\section{Initial and present publication}

We did not set limits on the length of the observation period.

\section{Setting}

\section{Initial and present publication}

We did not set limits on the setting such as type of country, year of recruitment or level of healthcare.

\section{Study design}

\section{Initial publication}

We included RCT and CCT evaluating permanent interstitial low-dose rate brachytherapy as monotherapy in patients with localised prostate cancer. The proportion of relevant patients was required to be at least $80 \%$ of the study population and the response rate of questionnaires was expected to be at least $70 \%$. For CCT to be included, comparable baseline characteristics between treatment groups or adjustment for imbalances of these data were required. Limits on year of publication or language were not applied.

\section{Present publication}

We included specifically the CCT that were excluded in the initial publication. 


\section{Search strategy}

The search strategy was reported previously. ${ }^{1}$

\section{Study selection}

In the present study, we selected only those 50 nonrandomised studies on PRO that were excluded from the evaluation in the initial publication. In the study selection process, two reviewers independently judged whether a study was included or excluded. Differences were resolved by discussion without the need for a third opinion.

\section{Data collection and analysis}

The reasons for exclusion were extracted independently by two reviewers. We sought for the following data: the inclusion criteria using the PICO framework, the proportion of response of participants to questionnaires, which was required to be at least $70 \%$, the reporting of separate baseline characteristics for each treatment group, the reporting of comparable baseline characteristics or adjustment for imbalances of these data such as the use of a Cox proportional hazard model and the reporting of statistics comparing treatment groups. Sufficient comparability was defined as a difference between baseline values that were not statistically significant. If a statistical test was not reported, we assumed two comparable values if the greater of the two values was less than $10 \%$ above the smaller one. We also required that authors reported effect measures and statistics testing the difference between treatment groups, for example, $p$ values or effect measures including 95\% CIs. Reporting of within group comparisons or before-and-after analyses was not deemed sufficient for inclusion. We did not apply a principal summary measure as we aimed to synthesise the information in a qualitative way.

\section{Assessment of risk of bias and quality of reporting}

Two reviewers independently assessed the quality of reporting of CCT according to the criteria specified in the previous paragraph. We did not specifically assess the risk of bias because we decided to exclude all papers with regard to a lack of reporting essential data.

\section{RESULTS}

Of a total of 462 full-text articles assessed for eligibility in the previously published systematic review, 31 studies were included and 431 studies were excluded. Among the 431 excluded articles, we identified 50 non-randomised studies that were reporting on PRO (figure 1). We evaluated the reasons for exclusion of those 50 studies and documented the results in table 1. In $42 \%$ (21 of 50) studies, the essential PICO framework was simply not met. In the majority of $58 \%$ (29 of 50) studies, the predefined requirement to apply measures to contain high risk of bias was not met. Of these 29 studies, 19 reported a proportion of patients responding to questionnaires of less than $70 \%$ or did not address this item. Baseline characteristics were not presented for treatment groups in three studies. In another six studies, baseline characteristics were not comparable between treatment groups or there was no confounder control in the analysis adjusting for important different factors such as mean age. The statistical comparison between treatment groups was deemed not appropriate in one study.

\section{DISCUSSION}

\section{Main results}

In summary, we found that roughly 4 of 10 excluded PRO studies did not meet the essential inclusion criteria using the PICO framework. This result is consistent with the problem of information retrieval aiming at a high recall and ending up with a low precision. The papers were obviously not relevant to the research question and we did not further examine the quality of reporting. We also found that roughly 6 of 10 excluded PRO studies met the PICO framework but did not provide the predefined requirements to care sufficiently enough for a low response of patients to questionnaires, for reporting baseline characteristics between treatment groups, for adjusting differences in those baseline characteristics between treatment groups and to use appropriate statistics to compare the outcome between treatment groups.

\section{Quality of reporting of PROs}

We identified a lack in the quality of reporting in many excluded CCT and wish to stress the importance of considering a series of requirements while conducting a study on PRO. Other authors have reported recently that, concerning disease-specific mortality or disease-free survival, the available studies did not show significant differences between treatment groups. ${ }^{13}{ }^{14}$ In the view of unknown or small differences in survival measures, the results of PRO studies could have a noticeable impact on medical decision-making. ${ }^{15}{ }^{16}$ None of the 50 excluded studies reported a non-responder analysis, although it is known that non-responders may have different attitudes than responders. Etter and Perneger ${ }^{17}$ concluded that low response rates may be associated with overestimating an effect and that the strength and direction of a non-response bias may depend on the mechanism of non-response. Therefore, results may be confounded if the proportion of included data not available for analysis such as data from non-responders or due to loss to follow-up is considerable. We believe that a value of $30 \%$ or more can be denoted as considerable. Lowering this threshold, for example, to $20 \%$, would have resulted in less included studies. However, others suggested that $20 \%$ or more loss would be sufficient for a high risk of bias threatening the validity of results. ${ }^{18}$ Concerning questionnaires, we recommend taking measures that are known to improve response rates. ${ }^{19} 20$ Edwards ${ }^{21}$ conducted a systematic review to identify effective strategies to increase the response to postal and electronic questionnaires. The authors found several strategies to increase the response, for example, 
Figure 1 Study flow. PICO: population, intervention, comparator, outcome; PRO: patient-reported outcomes; RCT: randomised controlled trial.

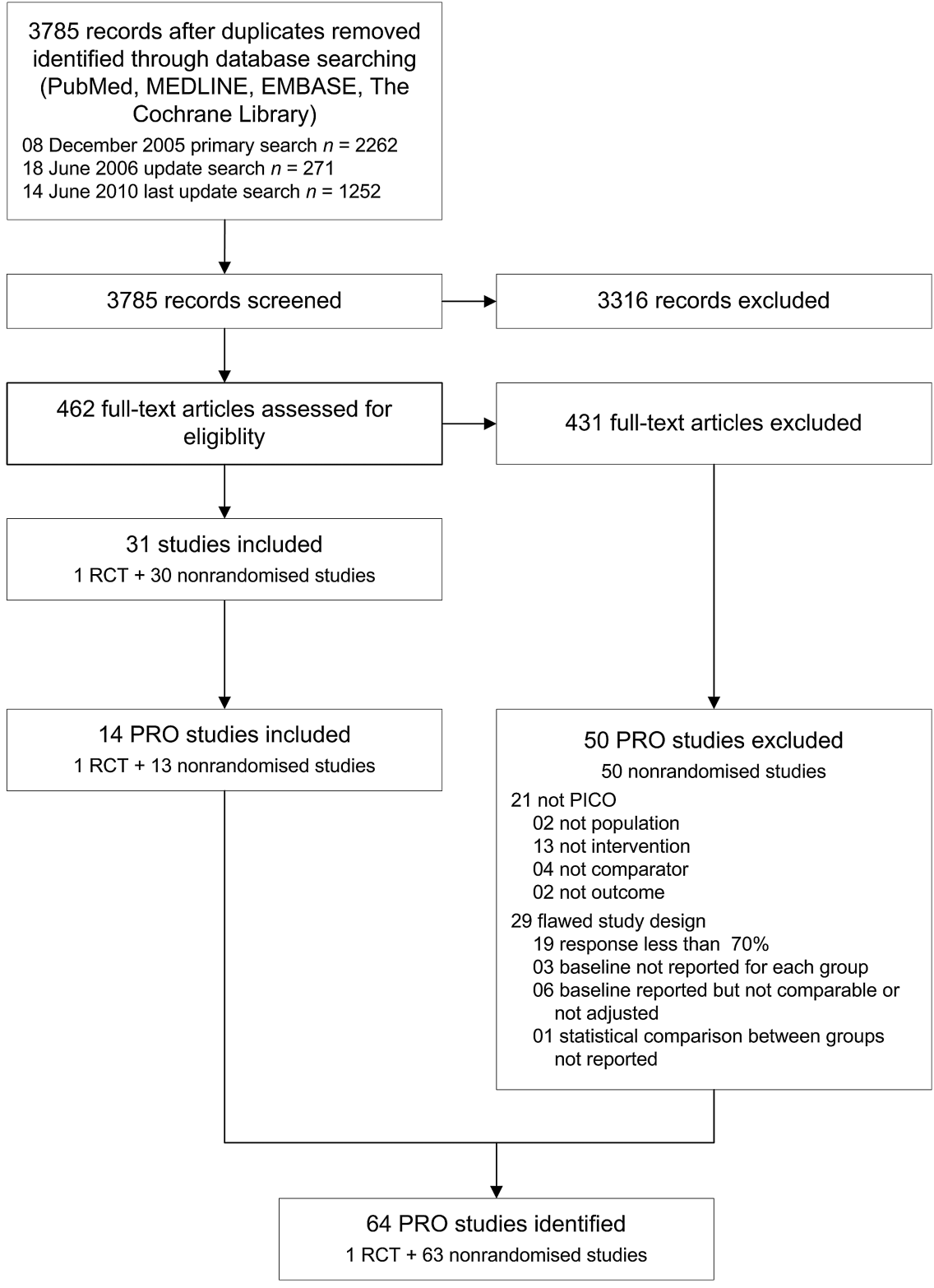

prenotification, follow-up contact, shorter questionnaires, mentioning an obligation to respond, university sponsorship, non-monetary incentives, a statement that others had responded, an offer of survey results, giving a deadline. We did not use a strict algorithm to differentiate between comparable and not comparable baseline values between treatment groups. A statistically significant difference was judged as not comparable. Non-significant differences were also regarded as not comparable if the difference was at least $10 \%$ of the lower of two values. Using this approach we tried to reduce subjective decisions. We are not aware of published strict algorithms in this matter.

\section{High risk of bias inherent in non-RCTs}

With a view to include only one RCT, the initial publication was based almost exclusively on CCT. However, the 
Table 1 Reasons for excluding PRO articles

\begin{tabular}{|c|c|c|c|c|c|c|c|c|c|}
\hline \multirow[b]{2}{*}{$\begin{array}{l}\text { Non-randomised } \\
\text { studies }\end{array}$} & \multicolumn{4}{|c|}{ Inclusion criteria } & \multicolumn{4}{|c|}{ Requirements to contain high risk of bias } & \multirow[b]{2}{*}{ Comments } \\
\hline & $\mathbf{P}$ & $\mathrm{I}$ & C & 0 & $\begin{array}{l}\text { Response } \\
\geq 70 \%\end{array}$ & $\begin{array}{l}\text { Baseline each } \\
\text { group }\end{array}$ & $\begin{array}{l}\text { Baseline } \\
\text { comparable/or adjusted }\end{array}$ & $\begin{array}{l}\text { Statistical comparison } \\
\text { between groups }\end{array}$ & \\
\hline Bacon et a ${ }^{9}$ & Yes & Yes & No & - & - & - & - & - & No concurrent group \\
\hline Ball et $a^{\beta 0}$ & Yes & Yes & No & - & - & - & - & - & Cryotherapy \\
\hline Befort et $a \beta^{11}$ & Yes & Yes & Yes & Yes & No & - & - & - & Low response \\
\hline Bergman et $a \beta^{32}$ & Yes & Yes & Yes & Yes & Yes & Yes & Yes & No & No appropriate test \\
\hline Bergman et $a^{\beta 3}$ & Yes & Yes & Yes & Yes & No & - & - & - & Low response \\
\hline Brandeis et $a^{\beta 4}$ & Yes & No & - & - & - & - & - & - & 29\% LDR-BT+EBRT \\
\hline Brown et $a \beta^{35}$ & Yes & No & - & - & - & - & - & - & EBRT \\
\hline Burnett et $a^{\beta 6}$ & Yes & Yes & Yes & Yes & No & - & - & - & Response not reported \\
\hline Chaikin et $a^{37}$ & No & - & - & - & - & - & - & - & Staging not reported \\
\hline Chen et $a^{\beta 8}$ & Yes & Yes & Yes & Yes & Yes & Yes & No & - & No confounder control \\
\hline Choo et a ${ }^{\beta 9}$ & Yes & Yes & Yes & Yes & Yes & No & - & - & Baseline not reported \\
\hline Clark et $a \uparrow^{40}$ & Yes & Yes & Yes & Yes & No & - & - & - & Low response \\
\hline Downs et $a f^{41}$ & Yes & Yes & Yes & Yes & Yes & Yes & No & - & No confounder control \\
\hline Eton et $a f^{42}$ & Yes & Yes & Yes & Yes & No & - & - & - & Low response \\
\hline Frank et $a t^{43}$ & Yes & Yes & Yes & Yes & No & - & - & - & Low response \\
\hline Fulmer et $a{ }^{44}$ & Yes & Yes & Yes & Yes & No & - & - & - & Response not reported \\
\hline Gore et $\left.a\right|^{45}$ & Yes & Yes & Yes & Yes & No & - & - & - & Low response \\
\hline Guedea et $a f^{46}$ & Yes & Yes & Yes & Yes & Yes & Yes & No & - & No confounder control \\
\hline Hashine et $a l^{17}$ & Yes & Yes & Yes & Yes & Yes & Yes & No & - & No confounder control \\
\hline Hashine et $a f^{48}$ & Yes & Yes & Yes & Yes & Yes & Yes & No & - & No confounder control \\
\hline Hervouet et $a{ }^{49}$ & No & - & - & - & - & - & - & - & $\begin{array}{l}\geq 20 \% \mathrm{~T} 3-\mathrm{T} 4 \text { in control } \\
\text { groups }\end{array}$ \\
\hline Hollenbeck et $a^{50}$ & Yes & No & - & - & - & - & - & - & LDR-BT+EBRT \\
\hline Jo et $a^{F^{1}}$ & Yes & No & - & - & - & - & - & - & $\begin{array}{l}\text { High-dose rate } \\
\text { brachytherapy }\end{array}$ \\
\hline Johnstone et $a^{F^{2}}$ & Yes & No & - & - & - & - & - & - & EBRT \\
\hline Joly et $a p^{53}$ & Yes & No & - & - & - & - & - & - & LDR-BT+EBRT \\
\hline Kakehi et $a^{54}$ & Yes & Yes & Yes & Yes & Yes & No & - & - & Baseline not reported \\
\hline Lev et $a^{\rho^{5}}$ & Yes & No & - & - & - & - & - & - & LDR-BT+EBRT \\
\hline Lilleby et $a^{66}$ & Yes & No & - & - & - & - & - & - & EBRT \\
\hline Litwin et $a^{57}$ & Yes & Yes & Yes & Yes & No & - & - & - & Low response \\
\hline Litwin et $a^{58}$ & Yes & No & - & - & - & - & - & - & $25 \%$ LDR-BT+EBRT \\
\hline Mehta et $a^{59}$ & Yes & Yes & Yes & No & - & - & - & - & "Fear of cancer"* \\
\hline Miller et $a^{60}$ & Yes & No & - & - & - & - & - & - & 44\% LDR-BT+EBRT \\
\hline Miller et $a^{61}$ & Yes & Yes & Yes & Yes & Yes & No & - & - & Baseline not reported \\
\hline Monahan et $a^{\rho^{2}}$ & Yes & Yes & Yes & Yes & No & - & - & - & Low response \\
\hline Namiki et $a^{\beta^{3}}$ & Yes & Yes & Yes & Yes & No & - & - & - & Low response \\
\hline Namiki et a $\beta^{4}$ & Yes & Yes & Yes & Yes & No & - & - & - & Low response \\
\hline
\end{tabular}




\begin{tabular}{|c|c|c|c|c|c|c|c|c|c|}
\hline \multirow[b]{2}{*}{$\begin{array}{l}\text { Non-randomised } \\
\text { studies }\end{array}$} & \multicolumn{4}{|c|}{ Inclusion criteria } & \multicolumn{4}{|c|}{ Requirements to contain high risk of bias } & \multirow[b]{2}{*}{ Comments } \\
\hline & $\mathbf{P}$ & I & C & 0 & $\begin{array}{l}\text { Response } \\
\geq 70 \%\end{array}$ & $\begin{array}{l}\text { Baseline each } \\
\text { group }\end{array}$ & $\begin{array}{l}\text { Baseline } \\
\text { comparable/or adjusted }\end{array}$ & $\begin{array}{l}\text { Statistical comparison } \\
\text { between groups }\end{array}$ & \\
\hline Ohashi et $a^{65}$ & Yes & Yes & Yes & Yes & No & - & - & - & Low response \\
\hline Pinkawa et $a^{66}$ & Yes & Yes & No & - & - & - & - & - & LDR-BT+hormonest \\
\hline Roach et $a^{67}$ & Yes & No & - & - & - & - & - & - & EBRT, single-arm trial \\
\hline Sanda et $a^{68}$ & Yes & Yes & Yes & Yes & No & - & - & - & Low response \\
\hline Schover et a ${ }^{69}$ & Yes & Yes & Yes & Yes & No & - & - & - & Low response \\
\hline Soderdahl et $a l^{70}$ & Yes & Yes & Yes & Yes & No & - & - & - & Low response \\
\hline Speight et $a l^{71}$ & Yes & Yes & Yes & Yes & No & - & - & - & Response not reported \\
\hline Stone et $a l^{72}$ & Yes & Yes & No & - & - & - & - & - & LDR-BT+hormones $†$ \\
\hline Trojan et $a l^{73}$ & Yes & Yes & Yes & Yes & No & - & - & - & Low response \\
\hline Tward et $a l^{74}$ & Yes & Yes & Yes & No & - & - & - & - & Mortality differs§ \\
\hline Valicenti et $a l^{75}$ & Yes & Yes & Yes & Yes & No & - & - & - & Response not reported \\
\hline $\begin{array}{l}\text { Van de Poll- } \\
\text { Franse et } a l^{76}\end{array}$ & Yes & No & - & - & - & - & - & - & LDR-BT+EBRT \\
\hline Wyler et $\mathrm{al}^{77}$ & Yes & Yes & Yes & Yes & Yes & Yes & No & - & No confounder control \\
\hline Zagar et al ${ }^{78}$ & Yes & No & - & - & - & - & - & - & LDR-BT+EBRT \\
\hline 'NO' counts & 2 & 13 & 4 & 2 & 19 & 3 & 6 & 1 & Total: 50 studies \\
\hline \multicolumn{5}{|c|}{ PICO not met: 21} & \multicolumn{4}{|c|}{ High risk of bias: 29} & \\
\hline
\end{tabular}

\section{-: not appropriate.}

*Mehta et a P $^{9}$ : no appropriate endpoint.

†Pinkawa et $a^{66}$; Stone et $a^{72}$ : neoadjuvant hormonal therapy.

$\S$ Tward et $\mathrm{al}^{\mathrm{T}}$ : non-disease-related mortality differs greatly.C, comparison of interest is radical prostatectomy, external beam radiotherapy, or no primary therapy; EBRT, external beam

radiotherapy; I, intervention of interest is low-dose rate brachytherapy as monotherapy; LDR-BT, permanent interstitial low-dose rate brachytherapy; O, outcome of interest is function, bother, or generic health-related quality of life; P, patients with localised prostate cancer; PRO, patient-reported outcomes. 
and $\mathrm{CCT}^{25}$ Guidelines for reporting observational studies have been published to improve their quality. ${ }^{5}$ Cox regression analysis, propensity-score-based analysis and instrumental variable analysis are methods that have been used for correction of confounding bias in nonrandomised studies. ${ }^{26}$ Different values of various outcome measures between groups may be simply caused by different baseline data in lieu of absent significant treatment effects. We accepted any type of method adjusting or stratifying for one or more known differences in baseline characteristics. Nevertheless, it should be kept in mind that methods of adjustment do not guarantee removal of bias and that residual confounding may remain high. ${ }^{22}$ Concerning the non-randomised design, we strongly recommend the use of methods for adjusting the results for confounders to aim for a lessbiased estimation of the treatment effect ${ }^{27}$ and the adoption of guidelines for the reporting of observational studies. $^{5}$

\section{Strengths and limitations}

The strengths of the present study are a comprehensive literature search, strict adherence to the projected methodology, the identification of a lack of quality in PRO studies and addressing the specific problems of PRO studies. We should consider some limitations: the study is confined to a single disease, so conclusions drawn from its results may not be generalisable to other diseases. The arbitrary limits set for inclusion of studies are responsible for the extent of excluded studies. These limits may be questioned by other investigators. During the re-evaluation of study quality, we found that one study fulfilled all criteria, although, this study was excluded in previous reports. ${ }^{28}$ The minimum follow-up of $70 \%$ for inclusion was set arbitrarily and others might find this threshold too low. We did not endorse the recently published reporting of PRO in randomised trials, an extension of the CONSORT statement. ${ }^{4}$ All included studies in the present review are nonrandomised. We think that the lack of randomisation is the prevailing issue. We did not endorse the CONSORT PRO extension for another reason. The included studies were published many years before this extension was published. There might be a need to develop an extension of the STROBE statement ${ }^{5}$ with the aim of improving the reporting of PRO in non-randomised studies. This extension could emphasise the specific challenges of reporting PRO with respect to lack of randomisation.

\section{CONCLUSIONS}

We found that a considerable number of nonrandomised controlled reporting PROs were excluded from a systematic review because of a lack of predefined reporting requirements. The assumed overall risk of bias was regarded as too high to consider the data of these studies for inclusion in the systematic review. With respect to the reporting of PROs, active efforts are required to improve the quality of reporting in nonrandomised controlled trials and to increase the number of randomised controlled trials.

Author affiliations

${ }^{1}$ Children's Hospital, University of Cologne, Cologne, Germany

${ }^{2}$ Outcomes Research Center, University of Illinois, Peoria, Illinois, USA

${ }^{3}$ FOM University of Applied Science for Economics \& Management, Essen,

Germany

${ }^{4}$ Department of Radiotherapy, University Hospital, Aachen, Germany

Contributors FP conceived, designed and performed the experiments. FP and MP analysed the data. FP, AML, CT and MP wrote the manuscript.

Funding This research received no specific grant from any funding agency in the public, commercial or not-for-profit sectors.

Competing interests None.

Provenance and peer review Not commissioned; externally peer reviewed.

Data sharing statement No additional data are available.

Open Access This is an Open Access article distributed in accordance with the Creative Commons Attribution Non Commercial (CC BY-NC 3.0) license, which permits others to distribute, remix, adapt, build upon this work noncommercially, and license their derivative works on different terms, provided the original work is properly cited and the use is non-commercial. See: http:// creativecommons.org/licenses/by-nc/3.0/

\section{REFERENCES}

1. Peinemann F, Grouven U, Bartel C, et al. Permanent interstitial low-dose rate brachytherapy for patients with localized prostate cancer-a systematic review of randomized and non-randomized controlled clinical trials. Eur Urol 2011;60:881-93.

2. Patrick D, Guyatt GH, Acquadro C. Chapter 17: Patient-reported outcomes. In: Higgins JPT, Green S, eds. Cochrane handbook for systematic reviews of interventions Version 510 [updated March 2011]. Chichester: The Cochrane Collaboration, 2011. www. cochrane-handbook.org

3. Schulz KF, Altman DG, Moher D, et al. CONSORT 2010 statement: updated guidelines for reporting parallel group randomised trials. PLOS Med 2010;7:e1000251.

4. Calvert M, Blazeby J, Altman DG, et al. Reporting of patient-reported outcomes in randomized trials: the CONSORT PRO extension. JAMA 2013;309:814-22.

5. von Elm E, Altman DG, Egger M, et al. The Strengthening the Reporting of Observational Studies in Epidemiology (STROBE) statement: guidelines for reporting observational studies. PLoS Med 2007;4:e296.

6. O'Connor D, Green S, Higgins JPT. Chapter 5: Defining the review question and developing criteria for including studies. In: Higgins JPTGreen S. eds. Cochrane handbook for systematic reviews of interventions Version 510 [updated March 2011] Chichester: The Cochrane Collaboration, 2011. www.cochranehandbook.org

7. Chang SM, Matchar DB, Smetana GW, Umscheid, CA. eds. Methods guide for medical test reviews. Rockville: Agency fo Healthcare Research and Quality; 2012, AHRQ Publication No: 12-EC017.

8. White $\mathrm{CM}$, Ip S, McPheeters $\mathrm{M}$, et al. Using existing systematic reviews to replace de novo processes in conducting comparative effectiveness reviews. Methods guide for comparative effectiveness reviews. Rockville: Agency for Healthcare Research and Quality, 2009.

9. Ebele JN, Sauter G, Epstein JI, et al. Pathology and genetics of tumours of the urinary system and male genital organs. Lyon: IARC Press, 2004.

10. Heidenreich A, Bolla M, Joniau S, et al. Guidelines on prostate cancer. Arnhem: European Association of Urology, 2011.

11. Thompson I, Thrasher JB, Aus G, et al. Prostate cancer. Guideline for the management of clinically localized prostate cancer: 2007 update. Linthicum: American Urological Association, 2007.

12. Nath R. Overview of brachytherapy physics. In: Thomadsen BR, Rivard MRButler W. eds. Brachytherapy physics. 2nd edn. Madison: Medical Physics Publishing, 2005.

13. Wilt TJ, MacDonald R, Rutks I, et al. Systematic review: comparative effectiveness and harms of treatments for clinically localized prostate cancer. Ann Intern Med 2008;148:435-48. 
14. Koukourakis G, Kelekis N, Armonis V, et al. Brachytherapy for prostate cancer: a systematic review. Adv Urol 2009;2009:327945

15. Rosenthal SA, Bittner NH, Beyer DC, et al. American Society for Radiation Oncology (ASTRO) and American College of Radiology (ACR) practice guideline for the transperineal permanent brachytherapy of prostate cancer. Int J Radiat Oncol Biol Phys 2011;79:335-41.

16. Crook JM, Gomez-Iturriaga A, Wallace K, et al. Comparison of health-related quality of life 5 years after SPIRIT (Surgical Prostatectomy [RP] versus Interstitial Radiation [BT] Intervention trial ACOSOG Z0070). Int J Radiat Oncol Biol Phys 2010;78(3 Suppl 1):S76.

17. Etter JF, Perneger TV. Analysis of non-response bias in a mailed health survey. J Clin Epidemiol 1997;50:1123-8.

18. Schulz KF, Grimes DA. Sample size slippages in randomised trials: exclusions and the lost and wayward. Lancet 2002;359:781-5.

19. Smeeth L, Fletcher AE. Improving the response rates to questionnaires. BMJ 2002;324:1168-9.

20. Brealey SD, Atwell C, Bryan S, et al. Improving response rates using a monetary incentive for patient completion of questionnaires: an observational study. BMC Med Res Methodol 2007;7:12

21. Edwards PJ, Roberts I, Clarke MJ, et al. Methods to increase response to postal and electronic questionnaires. Cochrane Database Syst Rev 2009;(3):MR000008.

22. Deeks JJ, Dinnes J, D'Amico R, et al. Evaluating non-randomised intervention studies. Health Technol Assess 2003; 7:iii-x, 1-173.

23. Ioannidis JP, Haidich AB, Pappa M, et al. Comparison of evidence of treatment effects in randomized and nonrandomized studies. JAMA 2001;286:821-30.

24. Reeves BC, Deeks JJ, Higgins JPT, et al. Chapter 13: Including non-randomized studies. In: Higgins JPT, Green S. eds. Cochrane handbook for systematic reviews of interventions Version 5.1.0 [updated March 2011]. Chichester: The Cochrane Collaboration, 2011. www.cochrane-handbook.org

25. Higgins JPT, Altman DG, Sterne JAC. Chapter 8: Assessing risk of bias in included studies. In: Higgins JPT, Green S. eds. Cochrane handbook for systematic reviews of interventions Version 5.1.0 [updated March 2011]. Oxford: The Cochrane Collaboration, 2011. www.cochrane-handbook.org

26. Schmoor C, Gall C, Stampf S, et al. Correction of confounding bias in non-randomized studies by appropriate weighting. Biom $J$ 2011:53:369-87.

27. Cox E, Martin BC, Van Staa T, et al. Good research practices for comparative effectiveness research: approaches to mitigate bias and confounding in the design of nonrandomized studies of treatment effects using secondary data sources: the International Society for Pharmacoeconomics and Outcomes Research Good Research Practices for Retrospective Database Analysis Task Force ReportPart II. Value Health 2009;12:1053-61.

28. Pinkawa M, Asadpour B, Piroth MD, et al. Health-related quality of life after permanent I-125 brachytherapy and conformal external beam radiotherapy for prostate cancer: a matched-pair comparison. Radiother Oncol 2009;91:225-31.

29. Bacon CG, Giovannucci E, Testa M, et al. The impact of cancer treatment on quality of life outcomes for patients with localized prostate cancer. J Urol 2001;166:1804-10.

30. Ball AJ, Gambill B, Fabrizio MD, et al. Prospective longitudinal comparative study of early health-related quality-of-life outcomes in patients undergoing surgical treatment for localized prostate cancer: a short-term evaluation of five approaches from a single institution. $J$ Endourol 2006;20:723-31.

31. Befort CA, Zelefsky MJ, Scardino PT, et al. A measure of health-related quality of life among patients with localized prostate cancer: results from ongoing scale development. Clin Prostate Cancer 2005;4:100-8.

32. Bergman J, Gore JL, Penson DF, et al. Erectile aid use by men treated for localized prostate cancer. J Urol 2009;182:649-54.

33. Bergman J, Kwan L, Litwin MS. Improving decisions for men with prostate cancer: translational outcomes research. J Urol 2010;183:2186-92.

34. Brandeis JM, Litwin MS, Burnison CM, et al. Quality of life outcomes after brachytherapy for early stage prostate cancer. J Urol 2000;163:851-7.

35. Brown MW, Brooks JP, Albert PS, et al. An analysis of erectile function after intensity modulated radiation therapy for localized prostate carcinoma. Prostate Cancer Prostatic Dis 2007;10:189-93.

36. Burnett AL, Aus G, Canby-Hagino ED, et al. Erectile function outcome reporting after clinically localized prostate cancer treatment. J Urol 2007;178:597-601.

37. Chaikin DC, Broderick GA, Malloy TR, et al. Erectile dysfunction following minimally invasive treatments for prostate cancer. Urology 1996;48:100-4.
38. Chen RC, Clark JA, Talcott JA. Individualizing quality-of-life outcomes reporting: how localized prostate cancer treatments affect patients with different levels of baseline urinary, bowel, and sexual function. J Clin Oncol 2009;27:3916-22.

39. Choo R, Long J, Gray R, et al. Prospective survey of sexual function among patients with clinically localized prostate cancer referred for definitive radiotherapy and the impact of radiotherapy on sexual function. Support Care Cancer 2010;18:715-22.

40. Clark JA, Inui TS, Silliman RA, et al. Patients' perceptions of quality of life after treatment for early prostate cancer. J Clin Oncol 2003;21:3777-84.

41. Downs TM, Sadetsky N, Pasta DJ, et al. Health related quality of life patterns in patients treated with interstitial prostate brachytherapy for localized prostate cancer-data from CaPSURE. J Urol 2003; $170: 1822-7$

42. Eton DT, Lepore SJ, Helgeson VS. Early quality of life in patients with localized prostate carcinoma: an examination of treatment-related, demographic, and psychosocial factors. Cancer 2001;92:1451-9.

43. Frank SJ, Pisters LL, Davis J, et al. An assessment of quality of life following radical prostatectomy, high dose external beam radiation therapy and brachytherapy iodine implantation as monotherapies for localized prostate cancer. J Urol 2007;177:2151-6.

44. Fulmer BR, Bissonette EA, Petroni GR, et al. Prospective assessment of voiding and sexual function after treatment for localized prostate carcinoma: comparison of radical prostatectomy to hormonobrachytherapy with and without external beam radiotherapy Cancer 2001;91:2046-55.

45. Gore JL, Kwan L, Lee SP, et al. Survivorship beyond convalescence: 48-month quality-of-life outcomes after treatment for localized prostate cancer. J Natl Cancer Inst 2009;101:888-92.

46. Guedea F, Ferrer M, Pera J, et al. Quality of life two years after radical prostatectomy, prostate brachytherapy or external beam radiotherapy for clinically localised prostate cancer: the Catalan Institute of Oncology/ Bellvitge Hospital experience. Clin Trans/ Oncol 2009;11:470-8.

47. Hashine $\mathrm{K}$, Kusuhara $\mathrm{Y}$, Miura N, et al. A prospective longitudinal study comparing a radical retropubic prostatectomy and permanent prostate brachytherapy regarding the health-related quality of life for localized prostate cancer. Jpn J Clin Oncol 2008;38:480-5.

48. Hashine K, Kusuhara Y, Miura N, et al. Health-related quality of life using SF-8 and EPIC questionnaires after treatment with radical retropubic prostatectomy and permanent prostate brachytherapy. Jpn $J$ Clin Oncol 2009;39:502-8.

49. Hervouet S, Savard J, Simard S, et al. Psychological functioning associated with prostate cancer: cross-sectional comparison of patients treated with radiotherapy, brachytherapy, or surgery. J Pain Symptom Manage 2005;30:474-84.

50. Hollenbeck BK, Dunn RL, Wei JT, et al. Neoadjuvant hormonal therapy and older age are associated with adverse sexual health-related quality-of-life outcome after prostate brachytherapy. Urology 2002;59:480-4.

51. Jo $\mathrm{Y}$, Junichi $\mathrm{H}$, Tomohiro $\mathrm{F}$, et al. Radical prostatectomy versus high-dose rate brachytherapy for prostate cancer: effects on health-related quality of life. BJU Int 2005;96:43-7.

52. Johnstone PA, Gray C, Powell CR. Quality of life in T1-3N0 prostate cancer patients treated with radiation therapy with minimum 10-year follow-up. Int J Radiat Oncol Biol Phys 2000;46:833-8.

53. Joly F, Brune D, Couette JE, et al. Health-related quality of life and sequelae in patients treated with brachytherapy and external beam irradiation for localized prostate cancer. Ann Oncol 1998;9:751-7.

54. Kakehi Y, Takegami M, Suzukamo Y, et al. Health related quality of life in Japanese men with localized prostate cancer treated with current multiple modalities assessed by a newly developed Japanese version of the Expanded Prostate Cancer Index Composite. J Urol 2007;177:1856-61.

55. Lev EL, Eller LS, Gejerman G, et al. Quality of life of men treated for localized prostate cancer: outcomes at 6 and 12 months. Support Care Cancer 2009;17:509-17.

56. Lilleby W, Fossa SD, Waehre HR, et al. Long-term morbidity and quality of life in patients with localized prostate cancer undergoing definitive radiotherapy or radical prostatectomy. Int J Radiat Oncol Biol Phys 1999;43:735-43.

57. Litwin MS, Sadetsky N, Pasta DJ, et al. Bowel function and bother after treatment for early stage prostate cancer: a longitudinal quality of life analysis from CaPSURE. $J$ Urol 2004;172:515-19.

58. Litwin MS, Gore JL, Kwan L, et al. Quality of life after surgery, external beam irradiation, or brachytherapy for early-stage prostate cancer. Cancer 2007;109:2239-47.

59. Mehta SS, Lubeck DP, Pasta DJ, et al. Fear of cancer recurrence in patients undergoing definitive treatment for prostate cancer: results from CaPSURE. J Urol 2003;170:1931-3. 
60. Miller DC, Sanda MG, Dunn RL, et al. Long-term outcomes among localized prostate cancer survivors: health-related quality-of-life changes after radical prostatectomy, external radiation, and brachytherapy. J Clin Oncol 2005;23:2772-80.

61. Miller DC, Wei JT, Dunn RL, et al. Use of medications or devices for erectile dysfunction among long-term prostate cancer treatment survivors: potential influence of sexual motivation and/or indifference. Urology 2006;68:166-71.

62. Monahan PO, Champion V, Rawl S, et al. What contributes more strongly to predicting QOL during 1-year recovery from treatment for clinically localized prostate cancer: 4-weeks-post-treatment depressive symptoms or type of treatment? Qual Life Res 2007;16:399-411.

63. Namiki S, Satoh T, Baba S, et al. Quality of life after brachytherapy or radical prostatectomy for localized prostate cancer: a prospective longitudinal study. Urology 2006;68:1230-6.

64. Namiki S, Kwan L, Kagawa-Singer M, et al. Distress and social dysfunction following prostate cancer treatment: a longitudinal cross-cultural comparison of Japanese and American men. Prostate Cancer Prostatic Dis 2009;12:67-71.

65. Ohashi T, Yorozu A, Toya K, et al. Serial changes of international prostate symptom score following $\mathrm{l}-125$ prostate brachytherapy. Int $J$ Clin Oncol 2006;11:320-5.

66. Pinkawa M, Fischedick K, Gagel B, et al. Association of neoadjuvant hormonal therapy with adverse health-related quality of life after permanent iodine-125 brachytherapy for localized prostate cancer. Urology 2006;68:104-9.

67. Roach M III, Chinn DM, Holland J, et al. A pilot survey of sexual function and quality of life following 3D conformal radiotherapy for clinically localized prostate cancer. Int J Radiat Oncol Biol Phys 1996;35:869-74.

68. Sanda MG, Dunn RL, Michalski J, et al. Quality of life and satisfaction with outcome among prostate-cancer survivors. $N$ Engl J Med 2008;358:1250-61.

69. Schover LR, Fouladi RT, Warneke CL, et al. Defining sexual outcomes after treatment for localized prostate carcinoma. Cancer 2002;95:1773-85.
70. Soderdahl DW, Davis JW, Schellhammer PF, et al. Prospective longitudinal comparative study of health-related quality of life in patients undergoing invasive treatments for localized prostate cancer. J Endourol 2005;19:318-26.

71. Speight JL, Elkin EP, Pasta DJ, et al. Longitudinal assessment of changes in sexual function and bother in patients treated with external beam radiotherapy or brachytherapy, with and without neoadjuvant androgen ablation: data from CaPSURE. Int J Radiat Oncol Biol Phys 2004;60:1066-75.

72. Stone NN, Marshall DT, Stone JJ, et al. Does neoadjuvant hormona therapy improve urinary function when given to men with large prostates undergoing prostate brachytherapy? J Urol 2010;183:634-9.

73. Trojan L, Harrer K, Schafer J, et al. [Complications and side effects of low dose rate brachytherapy for the treatment of prostate cancer: data on a 13year follow-up study from Mannheim]. Urologe $A$ 2007:46:1542-7.

74. Tward JD, Lee CM, Pappas LM, et al. Survival of men with clinically localized prostate cancer treated with prostatectomy, brachytherapy, or no definitive treatment: impact of age at diagnosis. Cancer 2006;107:2392-400.

75. Valicenti RK, Bissondtte EA, Chen C, et al. Longitudina comparison of sexual function after 3-dimensional conformal radiation therapy or prostate brachytherapy. $J$ Urol 2002;168:2499-504.

76. Van de Poll-Franse LV, Sadetsky N, Kwan L, et al. Severity of cardiovascular disease and health-related quality of life in men with prostate cancer: a longitudinal analysis from CaPSURE. Qual Life Res 2008;17:845-55

77. Wyler SF, Engeler DS, Seelentag W, et al. Health-related quality of life after radical prostatectomy and low-dose-rate brachytherapy for localized prostate cancer. Urol Int 2009;82:17-23.

78. Zagar TM, Stock RG, Cesaretti JA, et al. Assessment of postbrachytherapy sexual function: a comparison of the IIEF-5 and the MSEFS. Brachytherapy 2007;6:26-33. 